\title{
Limb length discrepancy after total hip arthroplasty: a systematic review
}

\author{
Pradeep Kumar Pathak, Rakesh Kumar Gupta*, Hari Singh Meena, Rajendra Fiske
}

Department of Orthopaedics, PGIMS, Rohtak, Haryana, India

Received: 12 June 2018

Revised: 13 August 2018

Accepted: 14 August 2018

\section{*Correspondence: \\ Dr. Rakesh Kumar Gupta, \\ E-mail: drrk60@rediffmail.com}

Copyright: () the author(s), publisher and licensee Medip Academy. This is an open-access article distributed under the terms of the Creative Commons Attribution Non-Commercial License, which permits unrestricted non-commercial use, distribution, and reproduction in any medium, provided the original work is properly cited.

\begin{abstract}
Correcting limb length inequality without compromising hip stability is one of the major intraoperative challenges in Total hip arthroplasty (THA) as it is a major cause of patient dissatisfaction and litigation against surgeon. Surgeons performing THA should aim to minimize Limb Length Discrepancy (LLD), and therefore should adopt a reliable method of doing so. Thus a reproducible technique which effectively reduces postoperative LLD without increasing operative time and is easy to apply is a need of time. Although various preoperative and intraoperative techniques are described in literature, none is universally applicable and is without limitations. We are presenting a review of 50 articles on limb length discrepancy after total hip arthroplasty, its implications and several techniques to avoid it. We suggest that every effort should be made to minimise postoperative Limb Length Discrepancy by combined use of preoperative and intraoperative techniques.
\end{abstract}

Keywords: Total hip arthroplasty, Limb length discrepancy, Hip replacement, Limb length inequality

\section{INTRODUCTION}

Limb length discrepancy (LLD) or limb length inequality after Total hip arthroplasty (THA) is not an uncommon problem after THA and is associated with patient dissatisfaction, poorer outcome after THA and has been a common cause for litigation against orthopaedic surgeons. ${ }^{1}$ Any residual LLD of less than $10 \mathrm{~mm}$ on AP radiographs is usually clinically acceptable, but there is no consensus over clearly unacceptable upper limit of LLD. Although various preoperative and intraoperative methods has been described in literature but still there is a lack of universally accepted, easy to use, reproducible and effective method of minimising LLD after THA. In this article we present a review of LLD, its incidence in general population after THA, risk factors, its implications and techniques to reduce LLD after THA.

\section{TYPES OF LLD}

LLD after THA can be described as true and apparent or structural and functional respectively. The structural or true leg-length inequality is caused by lengthening of the prosthetic head-neck distance and component malpositioning and is divided into 2 categories. 1) situations in which Limb-lengthening is direct result of component positioning: Such as when narrow femoral canal or high femoral cut leads to incomplete stem insertion \& a stem which sits too proud, or when the acetabular cup is placed too low, 2) Situations in which LLD is indirect result of component positioning: Such as when a surgeon increases the neck length to improve soft tissue restrains and to overcome intraoperative instability due to retroverted acetabular component. ${ }^{2}$ 
The apparent or functional leg-length inequality (FLLI) describes the amount that is attributable to other factors such as degenerative disease with scoliosis of the lumbar spine, causing obliquity of the pelvis and the tightness of the anterolateral soft tissues about the hip (Gluteus medius and minimus, tensor fascia lata, rectus femoris, psoas muscle). ${ }^{3}$

\section{PREVALENCE OF LLD}

Prevalence of LLD in general population is $90 \%$ and varies from $2.4 \mathrm{~mm}$ to $6.8 \mathrm{~mm}$ (mean magnitude of discrepancy is $5.2 \mathrm{~mm}$ ). Right leg is anatomically shorter in $53 \%$ to $75 \%$ of population as compared to left. Gender plays no role in amount of LLD. ${ }^{4}$ Due to the lack of agreement in the literature about significant level of LLD and a globally accepted LLD measurement protocol there are differences in both definitions and reported normative values. Asymptomatic LLD of $2 \mathrm{~cm}$ or more is common even in the non-operated asymptomatic general population and it is well recognised that both lengthening and shortening of this magnitude can occur after THA. ${ }^{4,5}$

Range of preoperative LLD in literature is reported to vary from $-70 \mathrm{~mm}$ to $+14 \mathrm{~mm}$ with mean preoperative LLD ranging from $-0.5 \mathrm{~mm}$ to $-7.5 \mathrm{~mm}^{6-12}$ After extensive literature review it appears that LLD after primary THA ranges from $1 \%$ to $27 \%$ and varies from 3 to $70 \mathrm{~mm}$ with a mean from 3 to $17 \mathrm{~mm}$. shortening is more common than lengthening and $\geq 1 \mathrm{~cm}$ LLD is noted in up to $50 \%$ of cases having LLD; of which only $15 \%-20$ $\%$ of patients require shoe correction for leg length equalization. $^{13}$

\section{IMPLICATIONS OF LLD}

LLD of $6 \mathrm{~mm}$ leads to pelvic tilt and scoliosis and LLD of $15 \mathrm{~mm}$ causes pelvic torsion. There is increased oxygen consumption in patients with LLD of $2-3 \mathrm{~cm}$ and increased heart rate in patients with LLD of $3-4 \mathrm{~cm}$. With a $4 \mathrm{~cm}$ limb-length discrepancy, there is a significant increase in plantar flexor activity in the shorter limb. Persons who have developed a LLD later in life are more debilitated by LLD of the same magnitude when compared to persons who have had LLD since childhood. $^{4}$

Severity of symptoms increases with increasing magnitude of LLD and patients with marked limb-length discrepancy may have substantial disability as a result of pain, limp, fatigue, nerve palsy and functional impairment. ${ }^{1}$ Usually nerve pain and palsy will tend to present earlier than mechanical and gait associated symptoms. ${ }^{14}$ Nerve injury is the most serious complication associated with limb length inequality. ${ }^{1}$ In a review of 23 THA complicated by peroneal and sciatic nerve palsy, Edwards et al noted an average lengthening of $2.7 \mathrm{~cm}$ for peroneal palsy and $4.4 \mathrm{~cm}$ for sciatic palsy. ${ }^{13,15}$
A person with LLD walks with decreased stance time and decreased step length on the shorter side, decreased walking velocity and increased cadence. He tries to hold the foot in equinus and drops pelvis with leaning of the ipsilateral aspect of the trunk on the shorter side, and flexion of the contralateral knee. The increased chances of development of degenative arthritis in the longer limb is, because it bears more weight and decreased coverage of femoral head by the acetabulum due to lowering the pelvis on the shorter side while walking. ${ }^{16}$

\section{MEASUREMENT OF LLD}

LLD can be quantified clinically and radiologically. Radiographic measurement is expected to be more accurate than clinical measurement in determining leg length discrepancy. ${ }^{17}$ There are two popular methods for clinical measurement of limb length : (a) 'Indirect method' which is done in standing position using lift blocks under the short leg and visually examining the level pelvis, and (b) 'Direct method' which is done in supine position and the distance of fixed bony landmarks (anterior superior iliac spine (ASIS) and the lateral or medial malleolus). ${ }^{4}$ Literature shows that the malleolus measurement is an inaccurate and imprecise method; with a mean difference of $8.6 \mathrm{~mm}$ in comparison to radiographs, with a intraobserver mean error of $1.1 \mathrm{~mm}{ }^{4}$

Two radiological techniques predominate in the literature and are widely used in clinical practice. In the methods described by Williamson and Reckling distance between most inferior point of Ischia and lesser trochanter is measured, whereas in method described by Woolson et al distance between inferior point of acetabular tear drop and lesser trochanter is measured. ${ }^{14,18}$ Neither Woolson's nor Williamson's method takes account of hip flexion or abduction deformity at the time of the x-ray (which tends to reduce the measured LLD) or any causes of LLD which does not involves the hip. ${ }^{14}$ Heaver et al reported that inter ischial line was best pelvic landmark for measurement of LLD, whereas Meermans et al reported teardrop line to be better. ${ }^{17,19}$ Meermans et al further reported that centre of femoral head should be taken as femoral reference point instead of lesser trochanter. ${ }^{19}$

Tipton et al reported that LLD calculated on AP radiograph of the pelvis are not comparable to LLD calculated on full length radiographs of limb and hence taking only pelvic radiograph to assess LLD is not adequate. $^{20}$

There is weak correlation between preoperative clinical and radiological LLD. Keršič et al in a series of 119 primary THA reported a difference of 5-8 $\mathrm{mm}$ between preoperative clinical and radiological LLD but, this difference decreased to 1-2 mm postoperatively. ${ }^{21}$ Sayednoor et al also supported these findings in their study. ${ }^{22}$ This postoperative improvement in correlation is probably on account of correction of any preoperative deformity existing at hip joint. On the other hand Gogia 
et al reported that clinical LLD measurement (ASISmedial malleolus) and a radiological measurement had excellent correlation $(\mathrm{ICC}=0.99){ }^{23}$ Beattie et al also supported these findings in their study. ${ }^{24}$ However their observation of good correlation between clinical and radiological measurement was probably on account of the fact that, in their study there was no deformity at the hip joint as all the subjects were healthy.

Patient perception of LLD and presence of actual LLD do not correlate well. patients who had lengthening were significantly more likely to detect LLD than those with shortening. ${ }^{25}$ One large-scale postal audit survey found that $30 \%$ of patients percieved that they developed LLD after THA, but on radiographic analysis only $36 \%$ of these patients had actual LLD of $\geq 5 \mathrm{~mm} .^{26}$ Similarly Konyves and Bannister also reported weak correlation between patient perception and actual LLD. ${ }^{25}$

Multiple studies have shown disagreement about association between radiologically evident LLD and surgeon based Harris hip score; patient based general health questionnaire, comfort, satisfaction and functional outcome of THA. ${ }^{25,27}$

\section{APPROACH TO MINIMIZING SYMPTOMATIC LLD}

Although LLD after THA altogether cannot be eliminated, the problem can be minimized. To prevent postoperative LLD and its associated problems, it's important to understand the various components of leg length assessment related to THA, including preoperative planning, identification of risk factors, intraoperative measurements and various methods for correction of LLD.

\section{IDENTIFICATION OF PATIENTS MOST AT RISK}

Atypical anatomy (excessive femoral bowing, narrow femoral canal \& poor bone stock) can cause difficulties in obtaining proper alignment of the components leading to LLD. This can be further complicated when using an uncemented femoral stem or in the obese patients. ${ }^{14}$ In the patients with short, varus neck of femur and short abductor muscles, abductor are sensitive to stretching and thus result in a tilted hemi-pelvis and apparent lengthening of operated leg. ${ }^{3}$ Short stature patients and obesity are other notable risk factors. ${ }^{14}$

Table 1: Mean and range of postoperative LLD in various studies in literature

\begin{tabular}{|c|c|c|c|}
\hline Study & Method used to reduce LLD & $\begin{array}{l}\text { Postoperative LLD } \\
\text { (mean in } \mathbf{m m} \text { ) }\end{array}$ & $\begin{array}{l}\text { Postoperative LLD } \\
\text { (range in } \mathrm{mm} \text { ) }\end{array}$ \\
\hline Plaas et $\mathbf{a l}^{6}$ & $\begin{array}{l}\text { Preoperative template technique and } \\
\text { intraoperative measurement from cone of } \\
\text { femur to lesser trochanter }\end{array}$ & 0.2 & -28 to $+20 \mathrm{~mm}$ \\
\hline Konyves and Bannister ${ }^{25}$ & No technique specified & -6.5 & -40 to +22 \\
\hline Maloney and Keeney ${ }^{54}$ & $\begin{array}{l}\text { Preoperative templating and } \\
\text { intraoperative clinical palpation of knees } \\
\text { and feet }\end{array}$ & -1.0 & -12 to +7 \\
\hline Papadopoulos et al ${ }^{9}$ & $\begin{array}{l}\text { Single suture applied on lateral pelvis and } \\
\text { intraoperative measurement by suture } \\
\text { thread }\end{array}$ & 1.58 & $-8 \mathrm{to}+7 \mathrm{~mm}$ \\
\hline Desai et al $^{46}$ & Application of Judd pin & +0.46 & -12 to +8 \\
\hline Hoffman et al $^{37}$ & $\begin{array}{l}\text { Preoperative templating and } \\
\text { intraoperative } \mathrm{x} \text { ray }\end{array}$ & +0.46 & -12 to +8 \\
\hline Barbier et $a^{48}$ & Intraoperative LOOD device & 2.31 & 0.04 to 6.96 \\
\hline Ranawat et al ${ }^{45}$ & $\begin{array}{l}\text { Steinman pin at infracotyloid groove and } \\
\text { caliper device }\end{array}$ & 2.62 & -7 to +9 \\
\hline Naito et al $^{7}$ & Steinman pin and caliper device & 0.5 & 0 to $2 \mathrm{~mm}$ \\
\hline Shiramizu et al $^{44}$ & L shaped caliper device & 2.1 & --- \\
\hline Lakshmanan et al ${ }^{51}$ & $\begin{array}{l}\text { Intraoperative length measurement by } \\
\text { taking } 2 \text { reference points on femur }\end{array}$ & -0.06 & -9 to +16 \\
\hline Halai et al $^{37}$ & $\begin{array}{l}\text { Preoperative templating and } \\
\text { intraoperative marking of femoral rasp }\end{array}$ & +1.3 & 0.2 to 9.3 \\
\hline Valle et al $^{53}$ & Preoperative templating & 2.8 & -6 to +10 \\
\hline Woolson et al ${ }^{18}$ & Preoperative template technique & $<10 \mathrm{~mm}$ & -20 to +20 \\
\hline Jasty et al $^{12}$ & Use of Jigs and calipers & 5.4 & -0.5 to +40 \\
\hline
\end{tabular}

There may be an apparent lengthening in the patients with pre-existing gluteal shortening and postoperative lengthening in these patients will further increase their pelvic tilt and sometimes patient will have to pivot on the shorter leg to place the longer leg on the ground. Patients with pre-existing asymptomatic LLD are less likely to 
tolerate any increase in their LLD and experience worse morbidity than would be associated with a similar LLD in other patients. ${ }^{14}$

\section{METHODS FOR MINIMISING LLD}

In literature various types of techniques have been used to minimise postoperative LLD which can be broadly divided in four broad categories. 1) Based on the preoperative templating to define the correct neck cut, the correct neck length of the femoral component and correct depth of femoral component insertion. 2) Based on the usage of a standard pelvic reference point and of a femoral reference point, and measurement of the distance of these two points as the limb length changes intraoperatively. 3) Based on intraoperative clinical tests such as the shuck test, the drop kick test, and the leg-toleg comparison 4) Based on navigation system's measurements. ${ }^{21}$

One other technique involving measurement of the gap between the limb edges of the abductor musculotendinous end and its insertion on the greater trochanter. Evaluation of the level of the center of the head in relation to the tip of the greater trochanter with the aid of a plate in a femoral head slot is also used intraoperatively for LLD measurement. ${ }^{28} \mathrm{~A}$ technique which uses intraoperative ultrasound to measure LLD is also described in literature. $^{29}$

Postoperative limb shortening after THA is less common but more tolerated than lengthening. In various studies postoperative lengthening After THA varied from 48 $62 \%$ whereas shortening have been seen in $10-32 \%$ of cases. ${ }^{6,25,30}$ Shortening is better tolerated because patients get physiologically and psychologically accustomed to this condition in preoperative phase and any increase in length postoperatively, starts causing discomfort, however extent of lengthening is utmost important for it to be clinically significant.

\section{PREOPERATIVE TECHNIQUES}

Most of the preoperative techniques are based on overlay templating and determining accurate position and size of implants. ${ }^{8,16,31-36}$ The use of templates is the first step in obtaining acceptable clinical results with regard to limb length. However, such use should be combined with a reliable intraoperative method to obtain optimal length. ${ }^{7}$ Hofmann et al evaluated the template technique and reported that in $50 \%$ of cases they had to change the plan during surgery. ${ }^{37}$ Magnification in radiographs and errors in measurement makes it extremely difficult to predict implant size accurately leading to incorrect prediction of size of implants in around $40 \%$ of cases, making it unreliable method. ${ }^{25,36}$ Halai et al were able to reduce mean postoperative to $1.3 \mathrm{~mm}$ (range $0.2-9.3 \mathrm{~mm}$ ) by Exeter technique and templating and concluded that Exeter technique was reproducible and was helpful in reducing incidence of leg-length discrepancy after
THA. ${ }^{38}$ Woolson et al were able to achieve desired level of neck osteotomy within $6 \mathrm{~mm}$ in $86 \%$ of patients and within $10 \mathrm{~mm}$ in $97 \%$ of patients. ${ }^{18}$

Template technique depends on intraoperative reproduction of centre of rotation of hip and femoral stem length which may not be as accurate. Further it does not take account of soft tissue tension across hip joint and hence may lead to instability around hip. Woolson et al reported that ninety-seven percent of the patients had a postoperative leg-length discrepancy that was less than $10 \mathrm{~mm}$ (with a range of -20 to $+20 \mathrm{~mm}$ ) but twenty-two of their 351 patients $(5 \%)$ sustained a postoperative dislocation of one hip during follow up, possibly on account of poor soft tissue tension. ${ }^{18}$ Valle et al in a retrospective study evaluated the utility of a preoperative planning with template technique and reported that acetabular component size was predicted exactly in $83 \%$; the femoral component size was predicted exactly in $78 \%$ and the average limb-length discrepancy was $1.71 \mathrm{~mm}$ (range -6 to $+20 \mathrm{~mm}){ }^{31}$

Measurement of limb length inequality, preoperative planning with radiographic templates and intraoperative corrections with measurements of limb lengths before and after the insertion of trial components using limb length callipers can reduce the incidence and magnitude of the problem of limb length discrepancy.

\section{INTRAOPERATIVE TECHNIQUES}

To date there are around 20 intraoperative techniques (Table 1) are described in literature and all are based on intraoperative measurement of distance between 2 reference points. Most of the techniques use one pelvic and one femoral reference points. While femoral reference point is usually GT in all the techniques, pelvic reference point may be pins inserted in Ilium, callipers, Judd pins, or a suture fixed in pelvis and varies in each technique. These techniques however have not been reliable because they are dependent upon accurate femur repositioning. Sarin et al reported that a 5 and 10 degrees of adduction/abduction intra-operatively can cause as much as $8 \mathrm{~mm}$ and $17 \mathrm{~mm}$ error in leg length measurement respectively. ${ }^{39}$ However effect on LLD due to incorrect flexion/extension repositioning is much less pronounced. Malrotation of the pelvis with respect to the femur (or operating room table) can also occur and contribute to leg length inequality and incorrect femoral offset restoration. Techniques using pins or jigs that are fixed at some distance away from the bone surface exaggerate the effect of rotational error because the measurements are made away from the rotational centre of the joint hence distance between the femur reference point and the joint centre should be minimised so that the deleterious effect of malrotation can be reduced. ${ }^{39}$

$\mathrm{Ng}$ et al in their review of literature on LLD after THA described about the importance of acetabular and femoral positioning and their effects on LLD. They stated that 
though external and internal reference marks may be used to guide acetabular implant positioning, fixed internal anatomical landmarks such as the transverse acetabular ligament, acetabular sulcus on the ischium, and the superior aspect of the acetabulum were less dependent on patient positioning and better indicators of implant positioning as compared to external reference points. They stated that eccentric inferior reaming of the acetabulum and placement of the cup below the planned level of the teardrop can increase the leg length. They also advised to take caution while deciding about the level of femoral osteotomy, as achieving the correct angle and level of the femoral osteotomy is important for seating the femoral implant accurately and avoiding leg length inequality. A high femoral neck cut may lead to more visible space in the medial calcar and the stem may appear undersized and changing to a larger stem to fill this void may lead to inadvertent lengthening of the limb. Similarly if the femoral osteotomy is too low, the femoral stem may not seat within the metaphysis and appear too large and changing to a smaller stem size to improve seating may lead to shortening of the limb. Lengthening the femoral neck alone will lead to increased femoral offset and limb length. ${ }^{40}$ These findings were also supported by Kayani et al in their review of literature on LLD after THA. ${ }^{41}$

Konyves and Bannister in a study of 90 patients undergoing primary total hip arthroplasty concluded that femoral component was principally responsible for LLD after THA and appropriate placement of the femoral component could significantly reduce postoperative LLD. $^{25}$

In THA preoperative templating should be used to predict the necessary length correction and plan femoral neck osteotomy level and combined with the techniques to reproduce it intraoperatively and accurate-positioning of the leg during measurements to ensure minimal LLD after THA. ${ }^{8}$

Although techniques which use large Steinmann pin have been described in literature, they have been criticized as unreliable as they are recommended to be removed and replaced during the surgery in between the measurements. ${ }^{13}$ Mcgee and Scott inserted a Steinmann pin into the pelvis 1.5 to $2 \mathrm{~cm}$ superior to the acetabulum and bent it into a $U$ and made a mark at the point where the free end of the $U$ contacts the greater trochanter and restoring the mark to the tip of the pin restored the preoperative length. ${ }^{43}$ Although sample size was 200 but they failed to substantiate their claim with any radiological or clinical data regarding LLD in their patients. ${ }^{13}$ Naito et al used Steinman pin and adjustable calliper to achieve intraoperative limb length correction. ${ }^{7}$ Bose and Shiramizu et al described similar techniques with similar results. ${ }^{43,44}$ Jasty et al in a series of 85 consecutive patients used sliding limb length calliper over pelvic reference wire to measure distance between pelvic reference point and femoral reference point and reported that 14 of 85 patients (16\%) had limb length inequality after surgery and out of these 6 patients needed a shoe raise. ${ }^{12}$ In this series of 85 THAs, 80 cases were still longer postoperatively. Major limitations of this study were its non blinded, retrospective nature and only pre operative usage of scanograms. ${ }^{12}$

A vertical Steinman pin can be inserted at the infracotyloid groove of the acetabulum and another mark over greater trochanter can be made with electrocautry. Leg is kept in 20 degree of flexion and internal rotation. ${ }^{45}$ Ranawat et al said that the points of reference in this method are close to centre of rotation of hip hence variations in measurements resulting from limb positions are less likely to occur. In their report postoperative LLD ranged from $-7 \mathrm{~mm}$ to $+9 \mathrm{~mm}$ (mean $2.62 \mathrm{~mm}$ ). Main Limitation of this technique is difficulty in accurate positioning of the pin due to large osteophytes at the posterior lip of acetabulum. ${ }^{45}$

Desai et al inserted Judd pin into the ileum just superior to the acetabulum, to provide a stable pelvic reference point and tied a suture to this pin. They tied a knot in the suture and a reference mark made with diathermy on the greater trochanter at the level of the knot, which was then used as a guide to either lengthen or maintain the same length based on preoperative templating/planning. ${ }^{46}$

Mihalko et al in their case report used a method in which a large unicortical fragment screw was placed above the superior rim of the acetabulum. They placed screwdriver in the hex-headed screw; and the distance was measured from the shaft of the screwdriver to a mark made with the cautery at the vastus tubercle on the lateral aspect of the greater trochanter. After the implantation of the prosthetic trial components, a check was made to ensure the appropriate limb length. ${ }^{47}$

Techniques using Steinman pin and adjustable calliper for intraoperative limb length measurement need a cumbersome and expensive device and also there is a need for a larger or a separate incision to accommodate these devices. ${ }^{7,43,44}$ Need to remove and reposit the Steinman pin and calliper device is an additional source of error. Loosening of the Steinmann pins, screw or Judd pin which is placed into the ilium or the supra-acetabular bone to provide a proximal reference point is another disadvantage. Loosening of pin in ilium makes it an unstable point of reference. To overcome this disadvantage, Woolson et al, used a specially designed calliper device with 3 triangular pins but it was invasive and required separate incision. ${ }^{18}$ Although they used this method in more than 200 patients and claimed this technique to be effective, they failed to substantiate their claim with clinical, radiological data and statistical evidence. $^{18}$

Barbier et al in a series of 58 THA evaluated the efficacy of 'length and offset optimization device' [LOOD] to optimize limb length and offset control. They reported 
mean LLD of $2.31 \mathrm{~mm}(0.04$ to $10.6 \mathrm{~mm})$ in patients operated on using the LOOD versus $6.96 \mathrm{~mm}$ without LOOD. $^{48}$

Fossae ovalis oriented acetabular centralized technology in THA can significantly correct abnormal hip center of rotation, thus reduce the relative and absolute limb-length inequality and improve the life quality of the patients. ${ }^{49}$ Clave et al used computer-assisted orthopedic surgery (CAOS) and were able to achieve desired leg length and offset within $\pm 5 \mathrm{~mm}$ in $83.3 \%$ and $88 \%$ of cases, respectively and only twenty-two of 321 patients required a heel wedge. Major limitation of this technique is non availability of CAOS at all the centres and requirement of a costly setup which increase cost of surgery. ${ }^{50}$

A technique using a skin suture below the iliac crest is described in literature. However different tension on the suture may result in different measurements, especially in old patients. $^{9}$

Lakshmanan et al marked points of reference within the femur to negate the variations in measurements with different limb positions during surgery. Difficulty to assess the prominent tubercle on the greater trochanter and in cases with deformed head or proximal femur was main disadvantage which makes this technique unreliable. $^{51}$

As compared to general anaesthesia, patients operated under spinal anaesthesia have higher LLD possibly due to increased soft tissue laxity after spinal anaesthesia which affects tests dependent on soft tissue tension unreliable and makes them erroneous. Thus while performing total hip arthroplasty under spinal anaesthesia, the surgeon should not rely on the shuck test to assess hip stability but should test range of motion for stability. ${ }^{52}$

Mastuda et al introduced a simple method to select an appropriate modular head during surgery so that LLD can be minimised. They calculated the ideal distance between the centre of the modular head and lesser trochanter on a preoperative AP radiograph. During surgery, they measured the actual distance between the centre of trial heads and the lesser trochanter with a ruler, and selected the head in which the measured distance was closest to this distance. ${ }^{33}$ Mean postoperative LLD was $<5 \mathrm{~mm}$ in patients operated with this technique. This technique can be used for non cemented THA only. Main disadvantage of this method as admitted by the authors was the difficulty in evaluation of acetabular component position, which is a key step in the technique. ${ }^{33}$ Similar technique was described by Valle et al using cemented components but the same limitations applied to this study as well. ${ }^{53}$

Affatato et al examined the validity of determining leg length differences using an ultrasound system. ${ }^{29}$ They measured the distance between three points, in millimetres, and the difference between preoperative and postoperative measurements represented change in the leg length. The method is non-invasive, not limited by radiation, easy, quick to use, and can be used for standard clinical screening. Studies are still in progress to resolve difficulties concerning the device sterilisation and the positioning of the entire set-up in a surgical unit. ${ }^{30}$

\section{CONCLUSION}

Limb length inequality following Total hip replacement is fairly common, though magnitude of inequality is variable. LLD of more than $10 \mathrm{~mm}$ is usually unacceptable and hence every effort should be made to minimise it. A comprehensive analysis of risk factors, preoperative extent of LLD and combined use of preoperative and intraoperative techniques may help to select appropriate implants and to adjust final leg lengths and minimise postoperative LLD.

\section{Funding: No funding sources \\ Conflict of interest: None declared \\ Ethical approval: Not required}

\section{REFERENCES}

1. Clark CR, Huddleston HD, Schoch EP, Thomas BJ. Leg-length discrepancy after total hip arthroplasty. J Am Acad Orthop Surg. 2006;14(1):38-45.

2. Parvizi J, Sharkey PF, Bissett GA, Rothman RH, Hozack WJ. Surgical treatment of limb-length discrepancy following total hip arthroplasty: J Bone Jt Surg-Am Vol. 2003;85(12):2310-7.

3. Ranawat CS, Rodriguez JA. Functional leg-length inequality following total hip arthroplasty. J Arthroplasty. 1997;12(4):359-64.

4. Gurney B. Leg length discrepancy. Gait Posture. 2002;15(2):195-206.

5. Knutson GA. Anatomic and functional leg-length inequality: A review and recommendation for clinical decision-making. Part I, anatomic leg-length inequality: prevalence, magnitude, effects and clinical significance. Chiropr Osteopat. 2005;13:11.

6. Plaass $\mathrm{C}$, Clauss $\mathrm{M}$, Ochsner PE, Ilchmann $\mathrm{T}$. Influence of leg length discrepancy on clinical results after total hip arthroplasty - A prospective clinical trial. Hip Int. 2011;21(4):441-9.

7. Naito M, Ogata K, Asayama I. Intraoperative limb length measurement in total hip arthroplasty. Int Orthop. 1999;23(1):31-3.

8. Maloney WJ, Keeney JA. Leg length discrepancy after total hip arthroplasty. J Arthroplasty. 2004;19(4):108-10.

9. Papadopoulos DV, Koulouvaris P, Aggelidakis GC, Tsantes AG, Lykissas MG, Mavrodontidis A. Intraoperative measurement of limb lengthening during total hip arthroplasty. Indian $\mathrm{J}$ Orthop. 2017;51(2):162.

10. Desai AS, Connors L, Board TN. Functional and radiological evaluation of a simple intra operative technique to avoid limb length discrepancy in total hip arthroplasty. Hip Int. 2011 Apr 5;21(2):192-8. 
11. Hofmann AA, Skrzynski MC. Leg-length inequality and nerve palsy in total hip arthroplasty: a lawyer awaits! Orthopedics. 2000;23(9):943-4.

12. Jasty M, Webster W, Harris W. Management of Limb Length Inequality During Total Hip Replacement. Clin Orthop. 1996;333:165.

13. Desai AS, Dramis A, Board TN. Leg length discrepancy after total hip arthroplasty: a review of literature. Curr Rev Musculoskelet Med. 2013;6(4):336-41.

14. McWilliams AB, Grainger AJ, O'Connor PJ, Redmond AC, Stewart TD, Stone MH. A review of symptomatic leg length inequality following total hip arthroplasty. Hip Int. 2013;23(1):6-14.

15. Edwards BN, Tullos HS, Noble PC. Contributory factors and etiology of sciatic nerve palsy in total hip arthroplasty. Clin Orthop. 1987;(218):136-41.

16. Bhave A, Paley D, Herzenberg JE. Improvement in gait parameters after lengthening for the treatment of limb-length discrepancy. JBJS. 1999;81(4):52934.

17. Heaver C, St Mart J-P, Nightingale P, Sinha A, Davis ET. Measuring limb length discrepancy using pelvic radiographs: the most reproducible method. Hip Int. 2013;23(4):391-4.

18. Woolson ST, Hartford JM, Sawyer A. Results of a method of leg-length equalization for patients undergoing primary total hip replacement. J Arthroplasty. 1999;14(2):159-64.

19. Meermans G, Malik A, Witt J, Haddad F. Preoperative Radiographic Assessment of Limblength Discrepancy in Total Hip Arthroplasty. Clin Orthop. 2011;469(6):1677-82.

20. Tipton SC, Sutherland JK, Schwarzkopf R. The Assessment of Limb Length Discrepancy Before Total Hip Arthroplasty. J Arthroplasty. 2016;31(4):888-92.

21. Keršič M, Dolinar D, Antolič V, Mavčič B. The Impact of Leg Length Discrepancy on Clinical Outcome of Total Hip Arthroplasty: Comparison of Four Measurement Methods. J Arthroplasty. 2014;29(1):137-41.

22. Sayed-Noor AS, Hugo A, Sjödén GO, Wretenberg P. Leg length discrepancy in total hip arthroplasty: comparison of two methods of measurement. Int Orthop. 2009;33(5):1189-93.

23. Gogia PP, Braatz JH. Validity and reliability of leg length measurements. J Orthop Sports Phys Ther. 1986;8(4):185-8.

24. Beattie P, Isaacson K, Riddle DL, Rothstein JM. Validity of derived measurements of leg-length differences obtained by use of a tape measure. Phys Ther. 1990;70(3):150-7.

25. Konyves A, Bannister GC. The importance of leg length discrepancy after total hip arthroplasty. Bone Jt J. 2005;87(2):155-7.

26. Wylde V, Whitehouse SL, Taylor AH, Pattison GT, Bannister GC, Blom AW. Prevalence and functional impact of patient-perceived leg length discrepancy after hip replacement. Int Orthop. 2009;33(4):9059.

27. White TO, Dougall TW. Arthroplasty of the hip: LEG LENGTH IS NOT IMPORTANT. Bone Jt J. 2002;84-B(3):335-8.

28. Rice IS, Stowell RL, Viswanath PC, Cortina GJ. Three Intraoperative Methods to Determine Limblength Discrepancy in THA. Orthopedics. 2014;37(5):e488-95.

29. Affatato S, Toni A. Leg length measurement: a new method to assure the correct leg length in total hip arthroplasty. Med Eng Phys. 2000;22(6):435-9.

30. Khanduja V, Tek V, Scott G. The effect of a neckretaining femoral implant on leg-length inequality following total hip arthroplasty. Bone Jt J. 2006;88(6):712-5.

31. Valle AGD, Slullitel G, Piccaluga F, Salvati EA. The precision and usefulness of preoperative planning for cemented and hybrid primary total hip arthroplasty. J Arthroplasty. 2005;20(1):51-8.

32. Woolson ST, Harris WH. A method of intraoperative limb length measurement in total hip arthroplasty. Clin Orthop. 1985;(194):207-10.

33. Matsuda K, Nakamura S, Matsushita T. A simple method to minimize limb-length discrepancy after hip arthroplasty. Acta Orthop. 2006;77(3):375-9.

34. Eggli S, Pisan M, Müller ME. The value of preoperative planning for total hip arthroplasty. J Bone Jt Surg Br. 1998;80-B(3):382-90.

35. Capello WN. Preoperative planning of total hip arthroplasty. Instr Course Lect. 1986;35:249-57.

36. Knight JL, Atwater RD. Preoperative planning for total hip arthroplasty. Quantitating its utility and precision. J Arthroplasty. 1992;7 Suppl:403-9.

37. Hofmann AA, Bolognesi M, Lahav A, Kurtin S. Minimizing leg-length inequality in total hip arthroplasty: use of preoperative templating and an intraoperative x-ray. Am J Orthop-BELLE MEAD-. 2008;37(1):18.

38. Halai M, Gupta S, Gilmour A, Bharadwaj R, Khan A, Holt G. The Exeter technique can lead to a lower incidence of leg-length discrepancy after total hip arthroplasty. Bone Jt J. 2015;97-B(2):154-9.

39. Sarin VK, Pratt WR, Bradley GW. Accurate femur repositioning is critical during intraoperative total hip arthroplasty length and offset assessment. J Arthroplasty. 2005;20(7):887-91.

40. Ng VY, Kean JR, Glassman AH. Limb-Length Discrepancy After Hip Arthroplasty: J Bone Jt SurgAm Vol. 2013;95(15):1426-36.

41. Kayani B, Pietrzak J, Hossain FS, Konan S, Haddad FS. Prevention of limb length discrepancy in total hip arthroplasty. Br J Hosp Med Lond Engl 2005. 2017;78(7):385-90.

42. McGee HM, Scott JH. A simple method of obtaining equal leg length in total hip arthroplasty. Clin Orthop. 1985;(194):269-70.

43. Bose WJ. Accurate limb-length equalization during total hip arthroplasty. Orthopedics. 2000;23(5):4336. 
44. Shiramizu K, Naito M, Shitama T, Nakamura Y, Shitama H. L-shaped caliper for limb length measurement during total hip arthroplasty. Bone Jt J. 2004;86(7):966-9.

45. Ranawat CS, Rao RR, Rodriguez JA, Bhende HS. Correction of limb-length inequality during total hip arthroplasty. J Arthroplasty. 2001;16(6):715-20.

46. Desai A, Barkatali B, Dramis A, Board TN. A simple intraoperative technique to avoid limb length discrepancy in total hip arthroplasty. The Surgeon. 2010;8(2):119-21.

47. Mihalko WM, Phillips MJ, Krackow KA. Acute sciatic and femoral neuritis following total hip arthroplasty. A case report. J Bone Joint Surg Am. 2001;83-A(4):589-92.

48. Barbier O, Ollat D, Versier G. Interest of an intraoperative limb-length and offset measurement device in total hip arthroplasty. Orthop Traumatol Surg Res. 2012;98(4):398-404.

49. Cao L, Tan L, Wu C, Lin X, Guo Y, Luo X, et al. Effect of reformative acetabular centralization technology on leg-length inequality in total hip arthroplasty (Zhongguo Xiu Fu Chong Jian Wai Ke Za Zhi Zhongguo Xiufu Chongjian Waike Zazhi). Chin J Reparative Reconstr Surg. 2014;28(2):213-7.
50. Clavé A, Sauleau V, Cheval D, Williams T, Lefèvre C, Stindel E. Can computer-assisted surgery help restore leg length and offset during THA? A continuous series of 321 cases. Orthop Traumatol Surg Res. 2015;101(7):791-5.

51. Lakshmanan P, Ahmed SM, Hansford RG, Woodnutt DJ. Achieving the required medial offset and limb length in total hip arthroplasty. Acta Orthopa Edica Belg. 2008;74(1):49.

52. Sathappan SS, Ginat D, Patel V, Walsh M, Jaffe WL, Di Cesare PE. Effect of anesthesia type on limb length discrepancy after total hip arthroplasty. J Arthroplasty. 2008;23(2):203-9.

53. Valle AGD, Slullitel G, Piccaluga F, Salvati EA. The precision and usefulness of preoperative planning for cemented and hybrid primary total hip arthroplasty. J Arthroplasty. 2005;20(1):51-8.

54. Maloney WJ, Keeney JA. Leg length discrepancy after total hip arthroplasty. J Arthroplasty. 2004;19(4):108-10.

Cite this article as: Pathak PK, Gupta RK, Meena HS, Fiske R. Limb length discrepancy after total hip arthroplasty: a systematic review. Int J Res Orthop 2018;4:690-7. 